\title{
Precise modeling of nutation and VLBI observations ${ }^{\star}$
}

\author{
J. Souchay ${ }^{1}$, M. Feissel ${ }^{1}$ and C. $\mathrm{Ma}^{2}$ \\ 1 Observatoire de Paris/DANOF, URA 1125 du CNRS, 61 Avenue de l'Observatoire, 75014 Paris, France \\ 2 NASA/Goddard Space Flight Center, Geodynamics Branch, Greenbelt, Md 20771, U.S.A.
}

Received August 16, 1994; accepted October 7, 1995

\begin{abstract}
Using geodetic and astrometric VLBI acquired between 1984-1994, we have determined coefficients in the nutation series with uncertainties of 10 microarcseconds. This level of accuracy is quite sufficient to differentiate between alternate theories of nutation. We show that small terms predicted using the Kinoshita \& Souchay (1990) rigid Earth theory of nutation revised by Souchay \& Kinoshita (1995), agree well with the VLBI results at periods where the non rigid Earth corrections are reliable. These terms are different or absent from the Kinoshita (1977) theory that is the basis for the standard IAU 1980 model. We propose a nutation series based on the Kinoshita \& Souchay theory using the Wahr (1979) transformation for a non rigid Earth that can be useful where the physical interpretation of the smaller terms is important. This series, called VKSNRE95.1, includes corrections to the nine largest terms derived from VLBI observations.
\end{abstract}

Key words: reference systems - Earth

\section{Introduction}

The theory of nutation developed by Woolard (1953) satisfied astronomical users for many years. It was replaced by more complete and more accurate IAU1980 theory (Seidelmann 1982) based on the work of Kinoshita (1977) and Wahr (1979), which ironically was quickly overtaken by modern astronomical observations such as Lunar Laser Ranging (LLR) and Very Long Baseline Interferometry (VLBI) that showed deficiencies in this theory at the level of several milliarcseconds (mas). The largest defects are ascribed to inadequacies in modeling of the response of the non rigid Earth. These involve the main terms of the series $(18.6 \mathrm{y}, 9.3 \mathrm{y}, 1.0 \mathrm{y}, 0.5 \mathrm{y}, 13.7 \mathrm{~d}$ and $13.6 \mathrm{~d})$ and have been actively investigated by several groups (e.g., Gwinn et al. 1986; Mc Carthy \& Luzum 1994; Walter \& Ma 1994). Souchay et al. (1995) give an extensive analysis of these terms, as well as of the precession constant and the Free Core Nutation component.

The comparison of observations with theory is complicated by three circumstances:

(1) Free modes of the Earth are expected to manifest themselves in the period range of 400-500 days.

(2) The still short time span of the VLBI data (15 years) precludes complete separation of the main terms

Send offprint requests to: J. Souchay

* Tables 2 and 3 are available in electronic form at the CDS via anonymous ftp 130.79.128.5 in the celestial motion of the Earth's pole, i.e., precession and the 18.6 year oscillation.

(3) The Kinoshita (1977) nutation series is truncated at 0.1 mas and does not consider the planetary effects on the Earth's axis.

Kinoshita \& Souchay (1990) have developed a more complete series, that retains all effects above 0.005 mas in longitude and obliquity, and also includes planetary effects, the largest of which has a 0.2 mas amplitude in longitude. While the IAU 1980 Theory of Nutation includes 106 luni-solar terms, the Kinoshita \& Souchay series revised by Souchay \& Kinoshita (1995), includes 270 independent luni-solar terms and 112 independent planetary terms. In addition to being more precise and complete, the Kinoshita \& Souchay theory also considers the contribution of coupling effects between the Earth's rotation and the orbital motion of the Moon, as well as nutationnutation cross effects, which influence some of the large terms.

Souchay et al. (1995) estimated corrections to the precession constant and the largest nutation terms from VLBI observations. This study concentrates on the ability of the presently available VLBI results to distinguish between the old and the new series for terms that are not expected to be modified by changes in geophysical modeling. For this purpose, the Kinoshita \& Souchay series which describes the motion of the axis of figure for a rigid Earth, is transformed into a series for the Non Rigid Earth (KSNRE) by use of Wahr's (1979) coefficients, which were 


\section{Planetary terms}

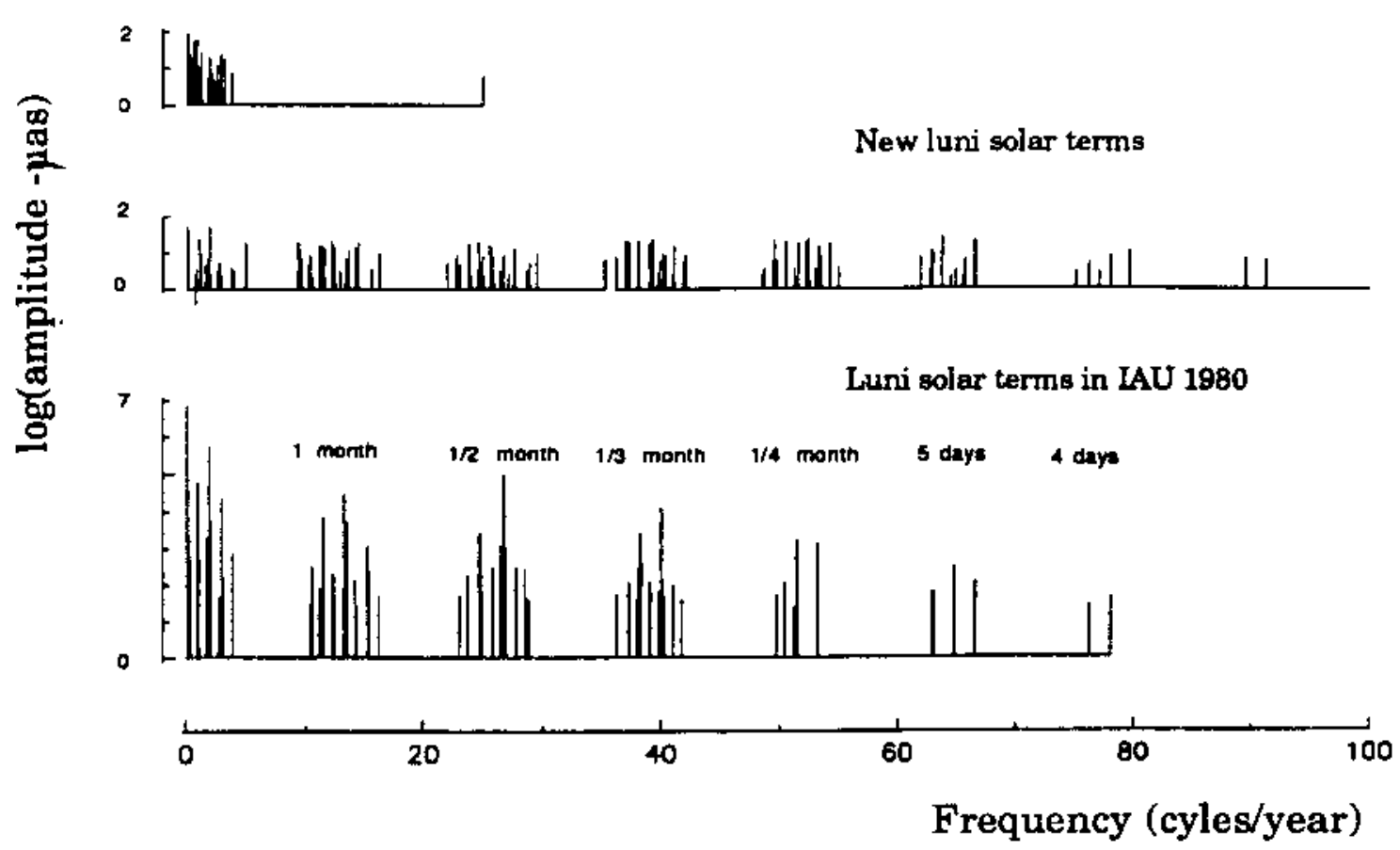

Fig. 1. a) The spectrum of the KSNRE model, showing the planetary contributions, and the luni-solar ones, present or not in IAU 1980

\section{Planetary terms}

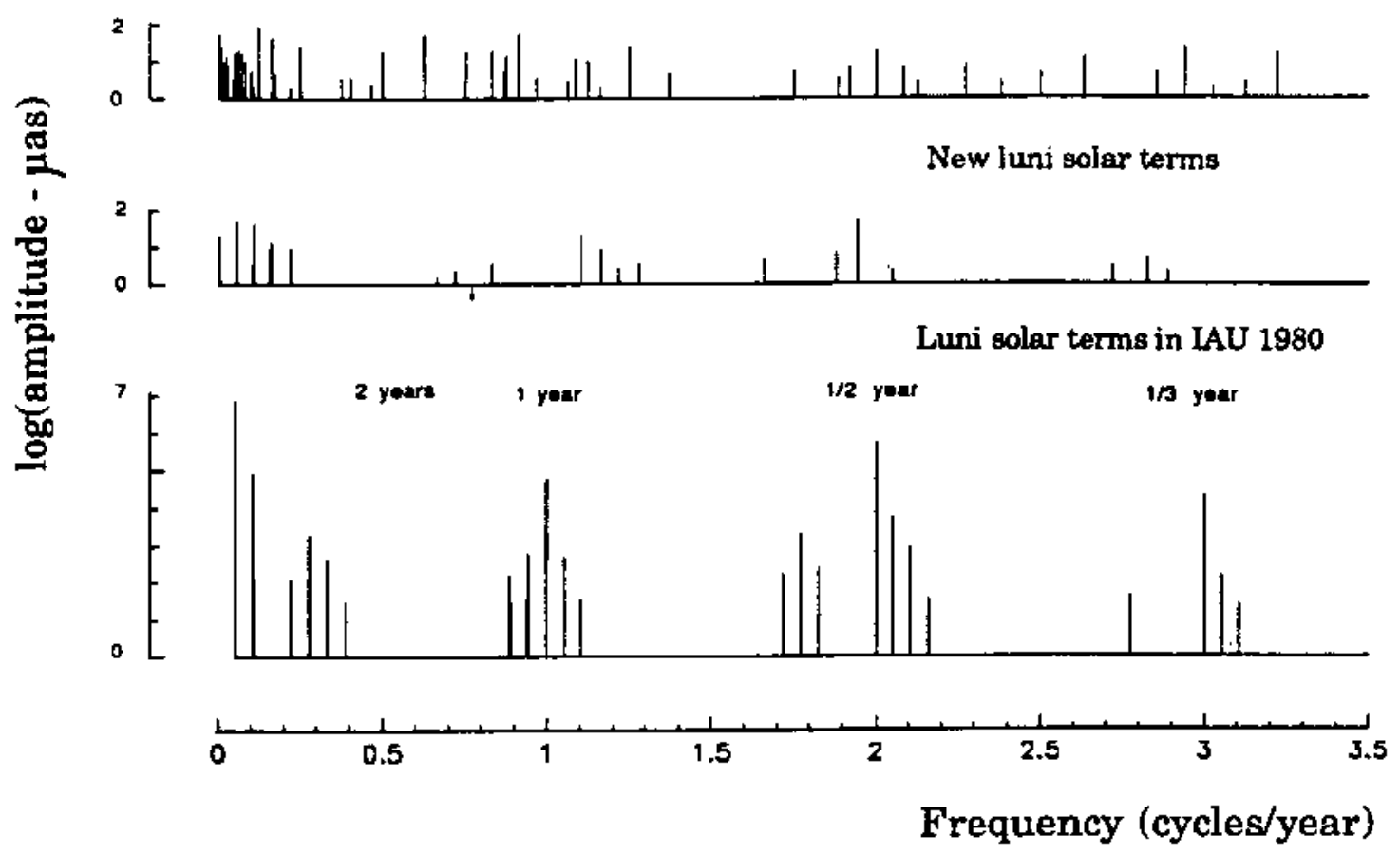

Fig. 1. b) Enlargement of the low frequency part of the spectrum of Fig. 1a 
Table 1. Luni-solar and planetary arguments used in the Kinoshita-Souchay theory. The values from ELP2000, VSOP82 and IAU 1976 can be found respectively in Chapront-Touzé \& Chapront (1983), Bretagnon (1982) and Lieske et al. (1977)

\begin{tabular}{|c|c|c|c|c|}
\hline Argument & Signification & $\begin{array}{r}\text { Value at J2000.0 } \\
\text { (degree) }\end{array}$ & $\begin{array}{r}\text { Rate } \\
(\text { deg./day })\end{array}$ & Origin \\
\hline $\begin{array}{l}\mathrm{l} \\
\mathrm{l} \\
\Omega \\
\mathrm{F} \\
\mathrm{D} \\
L_{V} \\
L_{E} \\
L_{M} \\
L_{J} \\
L_{S} \\
p_{A}\end{array}$ & $\begin{array}{r}\text { mean anomaly of the Moon } \\
\text { mean anomaly of the Sun } \\
\text { longitude of the node of the Moon } \\
\text { mean longitude of the Moon - } \Omega \\
\text { mean long. Moon - mean long. Sun } \\
\text { mean longitude of Venus } \\
\text { mean longitude of the Earth } \\
\text { mean longitude of Mars } \\
\text { mean longitude of Jupiter } \\
\text { mean longitude of Saturn } \\
\text { general precession in longitude } \\
\text { angle of rotation }\end{array}$ & $\begin{array}{r}134.96341 \\
357.52911 \\
125.04456 \\
93.27211 \\
297.85025 \\
181.97979 \\
100.46645 \\
355.43328 \\
34.35148 \\
50.07747 \\
0.00000\end{array}$ & $\begin{array}{r}13.0649930 \\
0.9856002 \\
-0.0529537 \\
13.2293500 \\
12.1907490 \\
1.6021305 \\
0.9856091 \\
0.5240328 \\
0.0830912 \\
0.0334597 \\
0.0000382 \\
360.98561\end{array}$ & $\begin{array}{l}\text { ELP2000 } \\
\text { ELP2000 } \\
\text { ELP2000 } \\
\text { ELP2000 } \\
\text { ELP2000 } \\
\text { VSOP82 } \\
\text { VSOP82 } \\
\text { VSOP82 } \\
\text { VSOP82 } \\
\text { VSOP82 } \\
\text { IAU1976 }\end{array}$ \\
\hline
\end{tabular}

\section{Longitude.sin(obliquity)}

\section{Unit: $0.001^{\prime \prime}$}
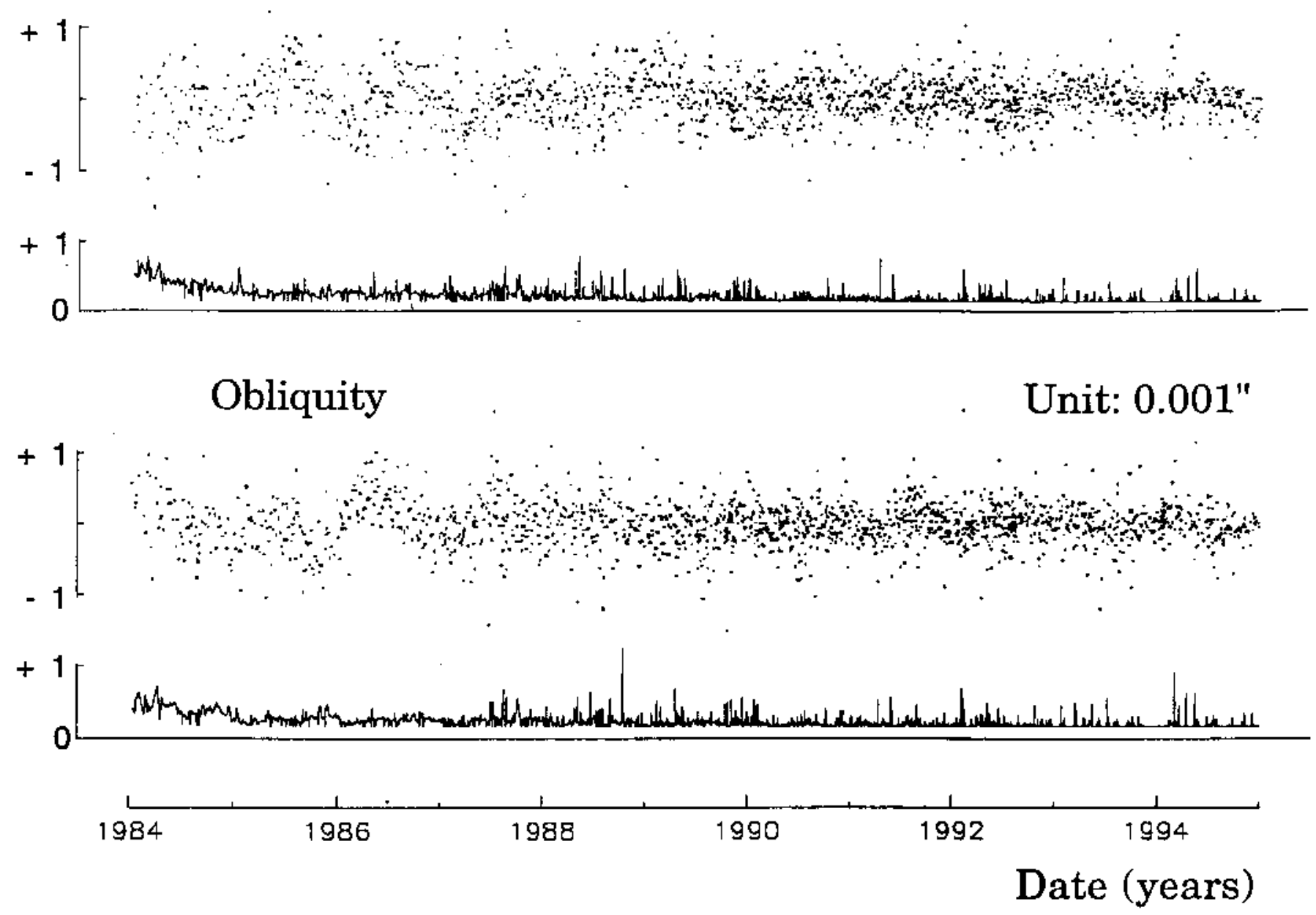

Fig. 2. The GSFC time series of the celestial pole offsets corrected by VKSNRE95.1 (dots), and their formal uncertainities (solid line), 1984-1994. Unit: 0.001" 


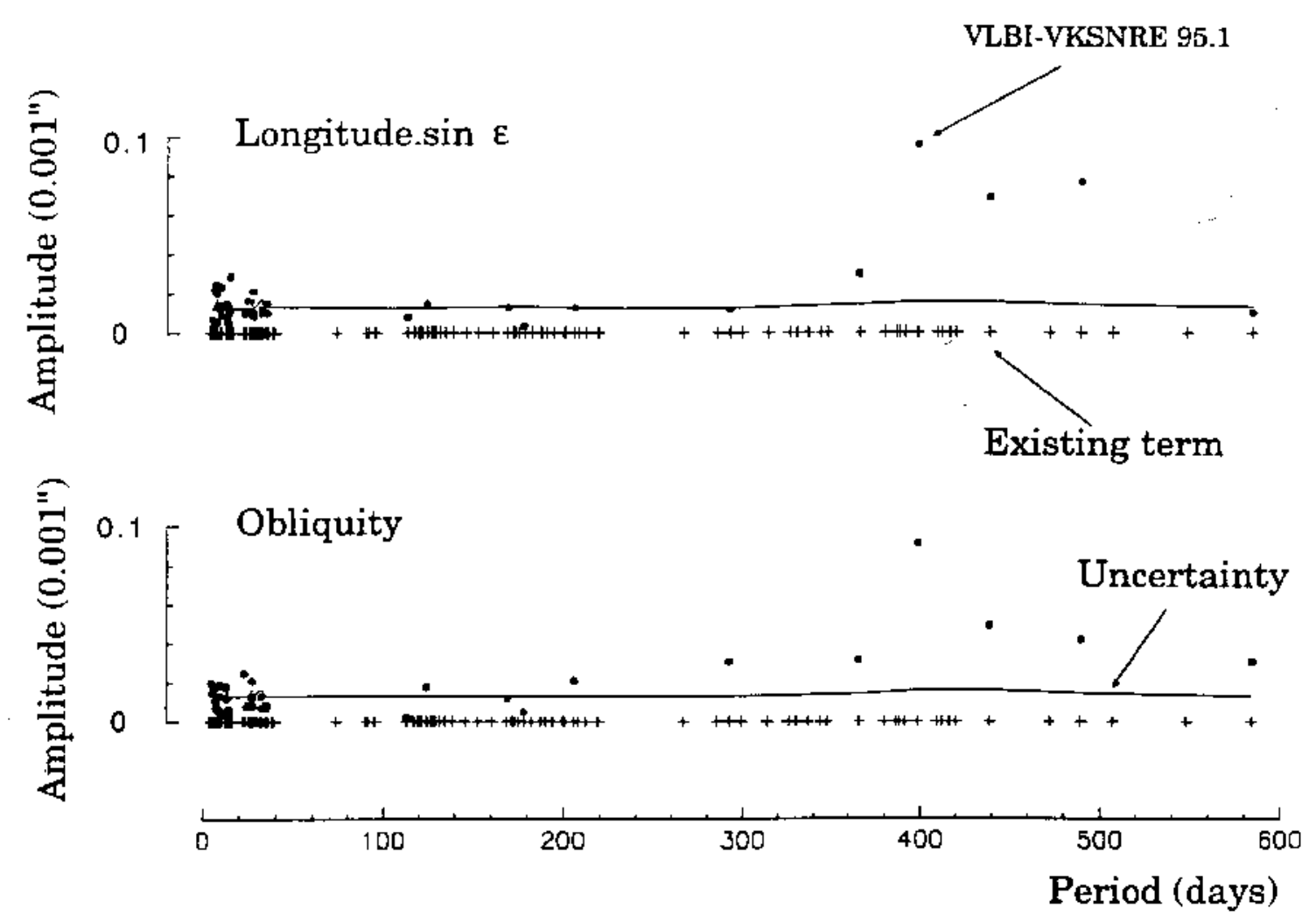

Fig. 3. Differences of estimated amplitudes of nutation terms with those predicted by the Kinoshita \& Souchay theory (.) for periods ranging from 5 to 600 days. The solid line gives the standard error of the estimations from VLBI observations. The positions of all existing lines in this part of the spectrum are shown $(+)$. Unit $=0.001^{\prime \prime}$

also used in the construction of the IAU 1980 Theory of the Nutation. In order to avoid interpretation difficulties resulting from the analysis problems mentioned above, this study concentrates on periods under 600 days, after appropriate treatment of the largest discrepancies of geophysical origin.

\section{The Kinoshita-Souchay nutation series for a non rigid Earth}

The accuracy of the transformation to a non rigid Earth depends not only on the accuracy of Wahr's coefficients, but also on the adopted value of the Free Core Nutation (FCN) frequency, as discussed by Zhu et al. (1990). Wahr (1979) used a 460-day period, whereas recent evaluations tend to give a value close to 433 days (Dehant 1992; Souchay et al. 1995). However, the defects in Wahr's coefficients affect only two categories of nutation terms: those with periods near the FCN period (roughly between 400 and 500 days), and the few coefficients with the largest amplitudes.

The astronomical arguments to be used with KSNRE are listed in Table 1. The spectral contributions of the various components in KSNRE are shown in Fig. 1: terms already included in the IAU 1980 theory of Nutation, lunisolar terms newly introduced, and planetary terms. The newly introduced lunisolar terms densify the spectrum in the annual and monthly bands and their harmonics. The planetary terms have a more even distribution, in particular in the band between 0.1 and $3 \mathrm{c} /$ year, and are becoming more interesting since the observational history of high precision VLBI has entered its second decade.

Notice that some of the coefficients included in the tables of nutation for a rigid Earth model given by Kinoshita \& Souchay (1990) have been subject to revision, other ones of small amplitude were ignored in these tables. The corrections relative to the two kinds of defects will be published soon (Souchay \& Kinoshita 1995). They have been taken into account in the VKSNRE95.1 series detailed below.

\section{The analysis and the VKSNRE95.1 series}

The data set considered is a time series of the celestial pole offsets $\delta \psi$ and $\delta \varepsilon$, derived by Ma et al. (1995) from 1700 24-hour VLBI sessions over 1980-1994, in the frame of a global analysis of the Earth's orientation. The same data set was used by Souchay et al. (1995) to estimate the 
Table 3. Correction to 42 mutation terms. 1st line: VKSNRE95.1-IAU 1980, 2nd line: VKSNRE95.1-VLBI (estimation), 3rd line: uncertainty of the estimation

$$
\begin{aligned}
& 1 \text { I' } F \text { D Om LV Le Ln Lj Ls pa (days) }{ }^{2} d \Psi \text { cos } \sin \text { cos (1) }
\end{aligned}
$$

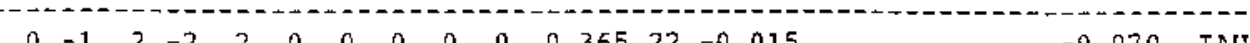

$$
\begin{aligned}
& \begin{array}{rrrrrrrrrrrrrrrr} 
& -1 & 2 & -2 & 2 & 0 & 0 & 0 & 0 & 0 & 0 & 365.22 & -0.015 & & 0.070 & \text { IAU }
\end{array} \\
& \begin{array}{lllll} 
\pm & 0.025 & 0.026 & 0.010 & 0.010
\end{array} \\
& \begin{array}{rrrrrrrrrrrrrrrr}
-2 & 0 & 0 & 2 & 0 & 0 & 0 & 0 & 0 & 0 & 0 & 205.89 & 0.032 & & 0.0 .057 & \text { IAU }
\end{array} \\
& \pm 0.023 \\
& \begin{array}{lllllllllllllll}
0 & 0 & -2 & 2 & -1 & 0 & 0 & 0 & 0 & 0 & 0 & 177.84 & 0.050 & 0.100 & \text { IAU }
\end{array}
\end{aligned}
$$

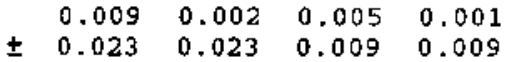

$$
\begin{aligned}
& \begin{array}{llllllllllllllll}
0 & 0 & -2 & 2 & 1 & 0 & 0 & 0 & 0 & 0 & 0 & 169.00 & -0.013 & -0.044 & \text { IAU }
\end{array} \\
& +0.023 \quad 0.023 \quad 0.009 \quad 0.009 \\
& \begin{array}{lllllllllllllllll}
-1 & -1 & 0 & 2 & 1 & 0 & 0 & 0 & 0 & 0 & 0 & 35.03 & -0.025 & 0.039 & \text { IAU }
\end{array} \\
& +0.0240 .0230 .0090 .009 \\
& \begin{array}{lllllllllllllllll}
-1 & -1 & 0 & 2 & -1 & 0 & 0 & 0 & 0 & 0 & 0 & 34.67 & -0.039 & 0.032 & \text { IAU }
\end{array}
\end{aligned}
$$

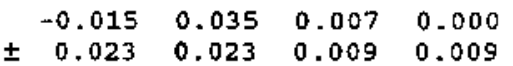

$$
\begin{aligned}
& \begin{array}{lllllllllllllllll}
-1 & 0 & 0 & 2 & 1 & 0 & 0 & 0 & 0 & 0 & 0 & 31.96 & -0.084 & & 0.001 & \text { IAU }
\end{array} \\
& \pm \quad 0.030 \quad 0.030 \quad 0.012 \quad 0.012 \\
& \begin{array}{rlllllllllllllllll}
-1 & 0 & 0 & 2 & 0 & 0 & 0 & 0 & 0 & 0 & 0 & 31.81 & -0.091 & 0.023 & 0.019 & 0.025 & -0.005 & 0.004
\end{array} \text { IAU } \\
& \begin{array}{lllll} 
\pm & 0.030 & 0.030 & 0.012 & 0.012
\end{array} \\
& \begin{array}{lllllllllllllll}
1 & 0 & 0 & 0 & -1 & 0 & 0 & 0 & 0 & 0 & 0 & 27.44 & 0.007 & -0.056 & \text { IAU }
\end{array} \\
& \begin{array}{rlll}
-0.021 & 0.002 & -0.008 & -0.001
\end{array} \\
& \begin{array}{llll}
0.022 & 0.022 & 0.009 & 0.009
\end{array} \\
& \begin{array}{lllllllllllllllll}
-1 & 2 & 0 & 2 & 0 & 0 & 0 & 0 & 0 & 0 & 0 & 27.09 & -0.008 & 0.000 & \text { IAU }
\end{array}
\end{aligned}
$$

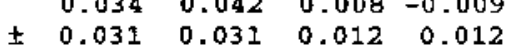

$$
\begin{aligned}
& \begin{array}{rrrrrrrrrrrrrrr}
-1 & 0 & 2 & 0 & 1 & 0 & 0 & 0 & 0 & 0 & 0 & 26.98 & -0.057 & & 0.076 \\
& & & & & & & & & & & 0.019 & -0.019 & -0.021 & 0.001
\end{array} \\
& \pm \quad 0.030 \quad 0.0310 .012 \quad 0.012 \\
& \begin{array}{lllllllllllllllll}
0 & 0 & -2 & 1 & -2 & 0 & 0 & 0 & 0 & 0 & 0 & 25.42 & -0.033 & & 0.031 & \text { IAU }
\end{array}
\end{aligned}
$$

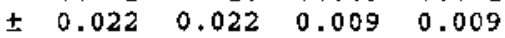

$$
\begin{aligned}
& \begin{array}{llllllllllllllllll}
-1 & 0 & -2 & 2 & -2 & 0 & 0 & 0 & 0 & 0 & 0 & 23.94 & 0.039 & & 0.034 & & 0.03 &
\end{array} \\
& \pm \quad 0.022 \quad 0.022 \quad 0.009 \quad 0.009
\end{aligned}
$$

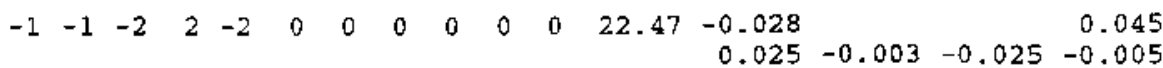

$$
\begin{aligned}
& \pm \quad 0.022 \quad 0.022 \quad 0.009 \quad 0.009 \\
& \begin{array}{lllllllllllllllll}
0 & 0 & 0 & 2 & 0 & 0 & 0 & 0 & 0 & 0 & 0 & 14.77 & 0.040 & & & 0.079 \\
& & & & & & & & & & & & 013 & 0.072 & -0.005 & 0.003
\end{array} \\
& \pm 0.022 \quad 0.022 \quad 0.009 \quad 0.009 \\
& \begin{array}{rllllllllllllllll}
-2 & 0 & 2 & 2 & 2 & 0 & 0 & 0 & 0 & 0 & 0 & 14.63 & 0.039 & & 0.040 & \text { IAU }
\end{array} \\
& \begin{array}{lllll} 
\pm & 0.022 & 0.022 & 0.009 & 0.009
\end{array} \\
& \begin{array}{lllllllllllllll}
0 & -1 & 2 & 0 & 1 & 0 & 0 & 0 & 0 & 0 & 0 & 14.16 & 0.035 & 0.035 & \text { IAU }
\end{array} \\
& -0.028-0.065-0.002-0.003 \\
& \begin{array}{lllll} 
\pm & 0.022 & 0.022 & 0.009 & 0.009
\end{array}
\end{aligned}
$$


Table 3. continued

$$
\begin{aligned}
& \text { Arguments Period Amplitudes }(0.001 ") \text { Type }
\end{aligned}
$$

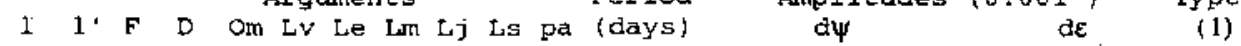

$$
\begin{aligned}
& \text { sin cos } \sin \cos \\
& \begin{array}{llllllllllllllllll}
2 & 0 & 0 & 0 & 0 & 0 & 0 & 0 & 0 & 0 & 0 & 13.78 & 0.025 & & 0.040 & \text { IA } \\
& & & & & & & & & & & & 0.018 & -0.019 & -0.003 & 0.005 &
\end{array} \\
& \pm \quad 0.022 \quad 0.022 \quad 0.009 \quad 0.009
\end{aligned}
$$

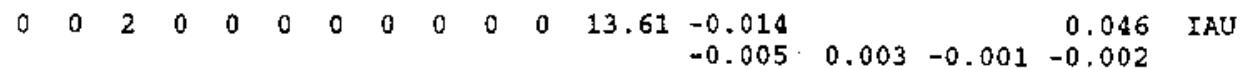

$$
\begin{aligned}
& \pm 0.030 \quad 0.0310 .012 \quad 0.012 \\
& \begin{array}{lllllllllllllll}
0 & 0 & 2 & 0 & -1 & 0 & 0 & 0 & 0 & 0 & 0 & 13.58 & -0.032 & 0.036 & \text { IAU }
\end{array} \\
& \begin{array}{rrrr}
-0.012 & 0.003 & 0.003 & 0.000 \\
\pm \quad 0.031 & 0.030 & 0.012 & 0.012
\end{array}
\end{aligned}
$$

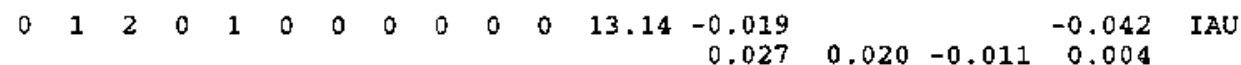

$$
\begin{aligned}
& \begin{array}{llll}
0.022 & 0.022 & 0.009 & 0.009
\end{array} \\
& \begin{array}{llllllllllllllllll}
-2 & 0 & -2 & 2 & -1 & 0 & 0 & 0 & 0 & 0 & 0 & 12.79 & -0.001 & & 0.046 & \text { IAU }
\end{array} \\
& +0.022 \quad 0.022 \quad 0.009 \quad 0.009 \\
& \begin{array}{lllllllllllllll}
0 & 0 & -4 & 2 & -2 & 0 & 0 & 0 & 0 & 0 & 0 & 12.66 & 0.009 & -0.039 & \text { IAU }
\end{array} \\
& \begin{array}{rrrr}
-0.022 & -0.032 & 0.015 & -0.010 \\
+\quad 0.022 & 0.022 & 0.009 & 0.009
\end{array} \\
& \begin{array}{lllllllllllllllll}
1 & 0 & 0 & 2 & 1 & 0 & 0 & 0 & 0 & 0 & 0 & 9.63 & 0.005 & & 0.049 & \text { IAU }
\end{array} \\
& \pm \quad 0.022 \quad 0.022 \quad 0.009 \quad 0.009 \\
& \begin{array}{rrrrrrrrrrrrrrrr}
-1 & 0 & 2 & 2 & 2 & 0 & 0 & 0 & 0 & 0 & 0 & 9.56 & -0.051 & 0.050 & \text { IAU }
\end{array} \\
& \begin{array}{llll}
0.022 & 0.022 & 0.009 & 0.009
\end{array} \\
& \begin{array}{lllllllllllllllll}
1 & 0 & 2 & 0 & 1 & 0 & 0 & 0 & 0 & 0 & 0 & 9.12 & -0.047 & 0.035 & -0.010 & -0.006 & -0.011
\end{array} \text { IAU } \\
& \pm \quad 0.0220 .0220 .009 \quad 0.009 \\
& \begin{array}{lllllllllllllllll}
-1 & 0 & 4 & 0 & 2 & 0 & 0 & 0 & 0 & 0 & 0 & 9.06 & 0.015 & 0.049 & & 0.04 &
\end{array} \\
& \pm \quad 0.022 \quad 0.022 \quad 0.009 \quad 0.009
\end{aligned}
$$

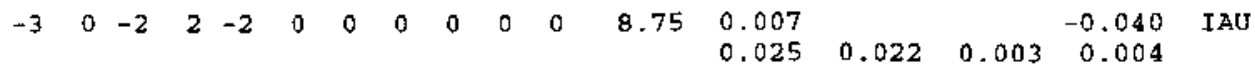

$$
\begin{aligned}
& \begin{array}{lllll} 
\pm & 0.022 & 0.023 & 0.009 & 0.009
\end{array}
\end{aligned}
$$

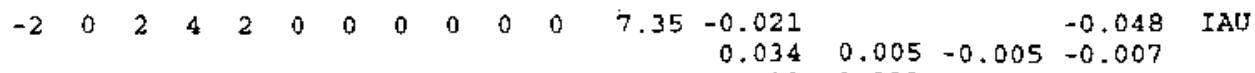

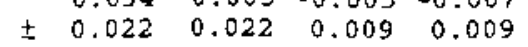

$$
\begin{aligned}
& \begin{array}{llllllllllllllrr}
0 & 0 & 2 & 2 & 2 & 0 & 0 & 0 & 0 & 0 & 0 & 7.10 & -0.042 & 0.038 & \text { IAU }
\end{array} \\
& \begin{array}{lllll} 
\pm & 0.031 & 0.031 & 0.012 & 0.012
\end{array} \\
& \begin{array}{lllllllllllllllll}
0 & 0 & 2 & 2 & 1 & 0 & 0 & 0 & 0 & 0 & 0 & 7.09 & 0.039 & 0.034 & \text { IAU }
\end{array} \\
& \pm 0.033 \quad 0.0310 .0120 .012
\end{aligned}
$$

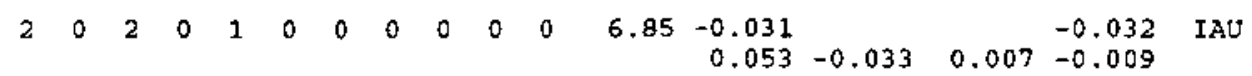

$$
\begin{aligned}
& \pm 0.0220 .0220 .009 \quad 0.009 \\
& \begin{array}{lllllllllllllllll}
-1 & 0 & 2 & 4 & 2 & 0 & 0 & 0 & 0 & 0 & 0 & 5.80 & 0.049 & & 0.035 & \text { IAU }
\end{array} \\
& \begin{array}{lllll} 
\pm & 0.022 & 0.022 & 0.009 & 0.009
\end{array} \\
& \begin{array}{lllllllllllllllll}
1 & 0 & 2 & 2 & 1 & 0 & 0 & 0 & 0 & 0 & 0 & 5.64 & -0.032 & & 0.034 & \text { IAU }
\end{array}
\end{aligned}
$$

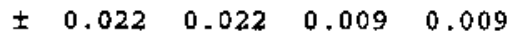


Table 3. continued

\begin{tabular}{|c|c|c|c|c|c|c|c|c|c|c|c|c|c|c|c|c|}
\hline \multirow[t]{2}{*}{1} & \multirow[t]{2}{*}{$1^{\prime}$} & \multirow[t]{2}{*}{$F$} & \multirow[t]{2}{*}{ D } & \multirow[t]{2}{*}{ Om } & \multirow{2}{*}{\multicolumn{3}{|c|}{$\begin{array}{l}\text { Arguments } \\
n \mathrm{LV} \text { Le Lm }\end{array}$}} & \multirow[t]{2}{*}{$\mathrm{Lj}$} & \multirow[t]{2}{*}{ Ls } & \multirow[t]{2}{*}{ pa } & \multirow[t]{2}{*}{$\begin{array}{l}\text { Period } \\
\text { (days) }\end{array}$} & \multicolumn{2}{|c|}{$\begin{array}{l}\text { Amplitudes } \\
\text { d } \psi\end{array}$} & \multicolumn{2}{|c|}{$s \quad \frac{(0.001 *)}{d E}$} & \multirow[t]{2}{*}{ Type } \\
\hline & & & & & & & & & & & & $\sin$ & $\cos$ & $\sin$ & $\cos$ & \\
\hline 2 & 0 & 2 & 2 & 1 & 0 & 0 & 0 & 0 & 0 & 0 & $\begin{array}{r}4.68 \\
\pm\end{array}$ & $\begin{array}{r}-0.018 \\
-0.011 \\
0.022\end{array}$ & $\begin{array}{r}-0.014 \\
0.022\end{array}$ & $\begin{array}{l}0.015 \\
0.009\end{array}$ & $\begin{array}{l}0.010 \\
0.013 \\
0.009\end{array}$ & $\overline{I \mu U}$ \\
\hline 0 & 0 & 0 & 0 & 0 & $1-$ & -1 & 0 & 0 & 0 & 0 & $\begin{array}{r}584.40 \\
\pm\end{array}$ & $\begin{array}{r}0.141 \\
-0.023 \\
0.023\end{array}$ & $\begin{array}{r}0.000 \\
-0.012 \\
0.024\end{array}$ & $\begin{array}{l}0.000 \\
0.031 \\
0.009\end{array}$ & $\begin{array}{r}-0.006 \\
0.003 \\
0.009\end{array}$ & P1. \\
\hline 0 & 0 & 0 & 0 & 0 & $2-$ & -4 & 0 & 0 & 0 & -2 & $\begin{array}{r}489.43 \\
\pm\end{array}$ & $\begin{array}{l}0.049 \\
0.121 \\
0.027\end{array}$ & $\begin{array}{r}0.000 \\
-0.150 \\
0.026\end{array}$ & $\begin{array}{r}0.000 \\
-0.034 \\
0.011\end{array}$ & $\begin{array}{r}0.020 \\
-0.024 \\
0.010\end{array}$ & Pl. \\
\hline 0 & 0 & 0 & 0 & 0 & 0 & 1 & $0-$ & -2 & 0 & 0 & $\begin{array}{r}438.30 \\
\pm\end{array}$ & $\begin{array}{r}-0.029 \\
-0.046 \\
0.028\end{array}$ & $\begin{array}{r}0.043 \\
-0.167 \\
0.029\end{array}$ & $\begin{array}{l}0.000 \\
0.040 \\
0.011\end{array}$ & $\begin{array}{r}0.007 \\
-0.029 \\
0.011\end{array}$ & p1. \\
\hline 0 & 0 & 0 & 0 & 0 & 0 & 1 & $0-$ & -1 & 0 & 0 & $\begin{array}{r}398.12 \\
\pm\end{array}$ & $\begin{array}{r}-0.148 \\
0.077 \\
0.028\end{array}$ & $\begin{array}{r}-0.004 \\
-0.226 \\
0.028\end{array}$ & $\begin{array}{l}0.000 \\
0.091 \\
0.011\end{array}$ & $\begin{array}{l}0.009 \\
0.029 \\
0.011\end{array}$ & Pl. \\
\hline 0 & 0 & 0 & 0 & 0 & $2-$ & -2 & 0 & 0 & 0 & 0 & $\begin{array}{r}292.20 \\
\pm\end{array}$ & $\begin{array}{r}-0.065 \\
0.022 \\
0.023\end{array}$ & $\begin{array}{l}0.000 \\
0.019 \\
0.022\end{array}$ & $\begin{array}{r}0.000 \\
-0.003 \\
0.009\end{array}$ & $\begin{array}{r}0.001 \\
-0.031 \\
0.009\end{array}$ & $\mathrm{Pl}$. \\
\hline 0 & 0 & 0 & 0 & 0 & 0 & 3 & 0 & -1 & 0 & 2 & $\begin{array}{r}124.18 \\
\pm\end{array}$ & $\begin{array}{r}0.056 \\
-0.027 \\
0.022\end{array}$ & $\begin{array}{l}0.002 \\
0.026 \\
0.022\end{array}$ & $\begin{array}{l}0.000 \\
0.002 \\
0.009\end{array}$ & $\begin{array}{r}-0.024 \\
0.018 \\
0.009\end{array}$ & P1. \\
\hline 0 & 0 & 0 & 0 & 0 & 2 & 0 & 0 & 0 & 0 & 2 & $\begin{array}{r}113.23 \\
\pm\end{array}$ & $\begin{array}{l}0.042 \\
0.018 \\
0.022\end{array}$ & $\begin{array}{l}0.000 \\
0.008 \\
0.022\end{array}$ & $\begin{array}{l}0.000 \\
0.002 \\
0.009\end{array}$ & $\begin{array}{r}-0.018 \\
-0.001 \\
0.009\end{array}$ & P1. \\
\hline
\end{tabular}

Note 1: The lunisolar terms in the IAU 1980 'Theory of Nutation are marked 'IAU', The planetary terms are marked 'Pl.'.

precession, nutation and FCN corrections of geophysical origin.

According to the standard definition of the celestial pole offsets (IERS, 1995), $\delta \psi$ and $\delta \varepsilon$ give the position of the celestial pole relative to that predicted by the IAU 1980 Theory of Nutation, respectively in longitude and in obliquity. To refer the observations to the more complete Kinoshita \& Souchay coefficients, the observations are first corrected for the difference between KSNRE and the IAU 1980 Theory of Nutation (except for the coefficients to be investigated, see hereafter), i.e., the difference between the models for terms already in the IAU 1980 Theory of Nutation and new terms solely from KSNRE. This corrected VLBI time series is then analysed for linear trends (precession and obliquity rate), for eight of the nine largest nutation terms that are affected with geophysical modeling (the 9.3 year coefficients are adopted for geophysical considerations), and for an empirical Free Core Nutation term with a period of 433 days (see Souchay et al. 1995). After fitting these last components by the way of VLBI, we get a new version of the KSNRE series which is corrected for unmodeled geophysical effects. These new series, called VKSNRE95.1, are listed in Table 2. Thus they consist in
8 nutation terms fitted to the observations, one derived from geophysical consideration, and 373 calculated purely analytically.

The new time series of the difference between the VLBI observations and the model are plotted in Fig. 2. Note that the evolution of the VLBI network and observation scheduling resulted in an improvement of precision with time to reach the level of 0.1 mas over 1991-93.

In a second step, the original series of $\delta \psi$ and $\delta \varepsilon$ are differenced from the predictions of VKSNRE 95.1 (Fig. 2 ), except for the terms to be investigated. The series of differences is then analysed by least-squares to determine whether there are significant disagreements between the observations and the theory. These disagreements are examined through a sample of 42 terms out of the 100 largest ones with periods between 5 and 600 days in KSNRE. The selection criterion is that the estimated parameters are correlated by less than 0.55 . The terms include 35 lunisolar terms and 7 planetary terms with theoretical amplitudes larger than 0.02 mas (in $\delta \psi \sin \varepsilon$ and $\delta \varepsilon$ ), i.e., five times smaller than the truncation limit of the IAU 1980 Theory of Nutation. The longest period retained in the sample is 584 days, a term due to the influence of Venus. 


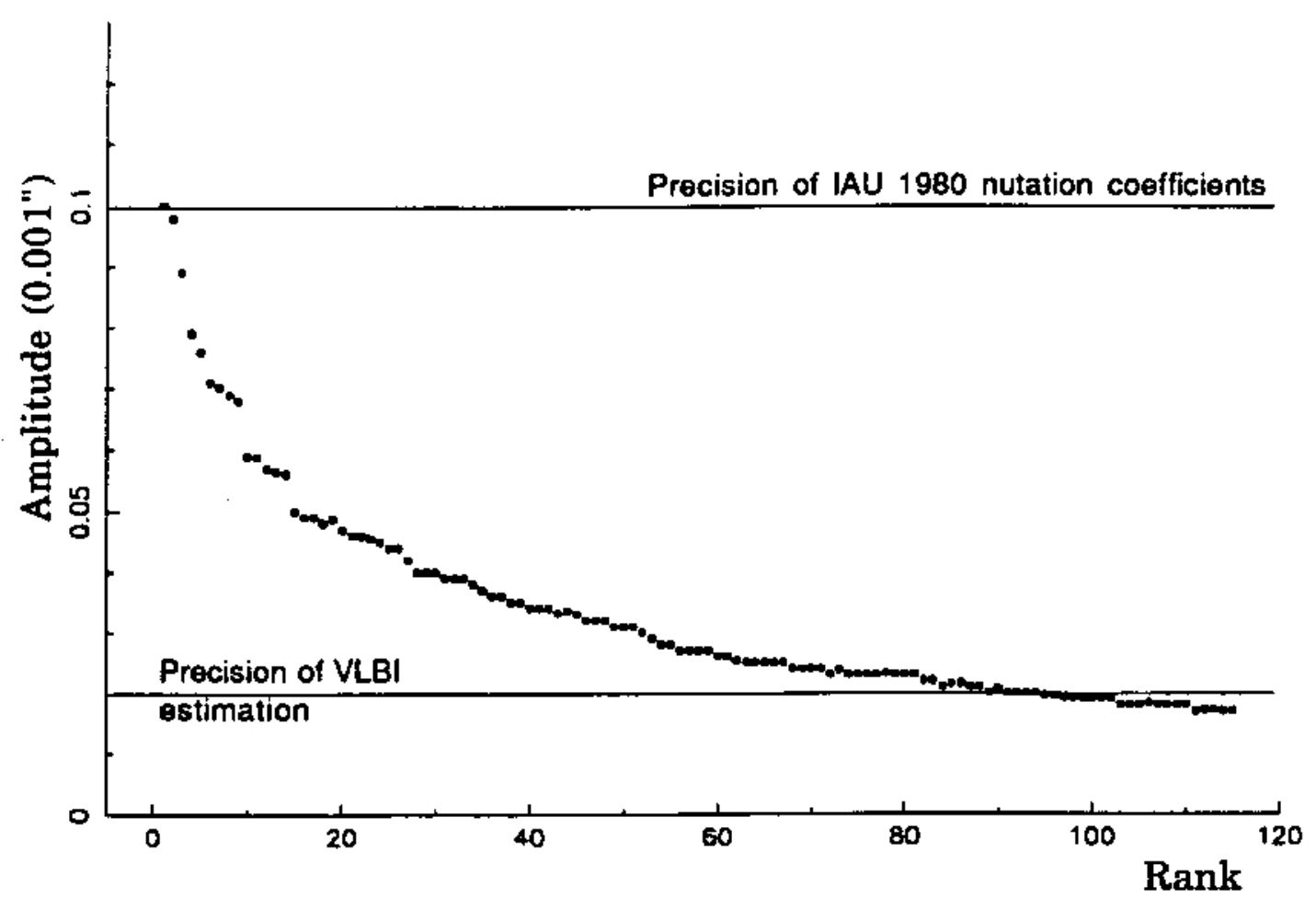

Fig. 4. Corrections to the IAU Theory of Nutation, as predicted by the Kinoshita-Souchay theory, for periods under 600 days. The terms are ordered in decreasing order of amplitude (in $\mathrm{d} \psi \sin \varepsilon$ and $\mathrm{d} \varepsilon$ ), not considering the ten largest terms, which have to be re-estimated for geophysical reasons. the solid line at the 0.02 mas level gives the standard error of the estimations of amplitudes with the present-day VLBI results. Unit: $0.001^{\prime \prime}$

The next periods for terms larger than 0.02 mas are 730, 943 and 1305 days (planetary terms).

The estimates obtained for the 42 terms are listed in Table 3. For each term, we give the estimated differences VKSNRE95.1-IAU 1980 and VKSNRE95.1-VLBI. Most VKSNRE95.1-IAU 1980 differences are at the level of 0.05 mas, as could be expected from the truncation of Kinoshita's series at 0.1 mas and the other mentioned defects. The listed uncertainities are one standard error of the least-squares estimate of the corresponding parameter. They are at the level of 0.01 mas on a single component (in $\delta \psi \sin \varepsilon$ and $\delta \varepsilon$ ). It can be seen that for most terms the difference VKSNRE95.1-IAU1980 is significantly larger than VKSNRE95.1-VLBI, indicating that the new series agrees much better with the observations.

The agreement of the VKSNRE95.1 terms with the VLBI results is remarkable, as can be seen in Fig. 3. The only significant discrepancies are for terms near large dissipative oscillations, around one year and half year (seasonal fluid effects) and in the 400-500 days band where free modes are expected to be active. Differences up to 0.07 mas (in $\delta \psi \sin \varepsilon$ and $\delta \varepsilon$ ) are found in the in-phase as well as in the out-of-phase components for the terms with period 398, 438 and 486 days. Another group, with amplitude discrepancies up to 0.02 mas, also in-phase as well as out-of-phase, is in the band 9-35 days. This second anomaly is consistent with the fact that while the standard deviation of the observations from the VKSNRE95.1 model is at the level of the VLBI formal uncertainties for a single determination of $\delta \psi \sin \varepsilon$ or $\delta \varepsilon( \pm 0.2$ mas) for periods longer than about one month, it is higher ( \pm 1 mas) for shorter periods. Further investigation of the VLBI results is needed to explain these relatively high discrepancies.

\section{Conclusion}

This study shows that the VLBI results available in 1993 are able to confirm the validity of the Kinoshita-Souchay model of luni-solar-planetary nutation down to the level of \pm 0.01 mas, notwithstanding the remaining questions concerning the response of a nonrigid Earth and their implications on the few largest terms in the series.

The improvement relative to the IAU 1980 Theory of Nutation that is brought by both VLBI and the KinoshitaSouchay nutation theory for a rigid Earth model is illustrated in Fig. 4 for the terms with periods under 600 days. The terms are organized in decreasing order of magnitude (in $\delta \psi \sin \varepsilon$ and $\delta \varepsilon$ ), not considering the eight largest terms, which have been re-estimated for geophysical reasons. The line at 0.02 mas shows the level of uncertainty of the estimation of amplitudes based on the VLBI results 
available in 1995. The precision of the IAU 1980 Theory of Nutation is also shown. It is clear that the combined use of the two types of information provides an excellent basis for further investigating remaining problem areas, such as the $9-35$ days or the $400-500$ days bands.

For future progress in the understanding of the nutation and precession of the planet Earth, the continuation of VLBI observations with the present day accuracy will be needed.

Acknowledgements. The first author is indebted to Dr. Kinoshita (Tokyo National Astronomical Observatory) for giving him the possibility to perform computations in his laboratory and to Dr. Niimi for carefully checking the transformations from Wahr's theory.

\section{References}

Bretagnon P., 1982, A\&A 114, 278

Chapront-Touzé M., Chapront J., 1983, A\&A 124, 50

Dehant V., 1992, Actes Journées Systèmes de Référence. In:
Capitaine N. (ed.), p. 63

Gwinn C.R., Herring T.A., Shapiro I.I., 1986, J. Geophys. Res. B5, 4755

IERS, 1995, 1993 IERS Annual Report, Obs. de Paris, p. I-11 Kinoshita H., 1977, Celest. Mech. 26, 296

Kinoshita H., Souchay J., 1990, Celest. Mech. 48, 187

Lieske J.H., Lederle T., Fricke W., Morando B., 1977, A\&A 124,50

Ma C., Ryan J.W., Gordon D., 1995, IERS Technical Note 19. In: Charlot (ed.), p. R-13

Mc Carthy D.D., Luzum B.J., 1994 (in preparation)

Seidelmann P.K., 1982, Celest. Mech. 27, 79

Souchay J., Feissel M., Bizouard C., Capitaine N., Bougeard M., 1995, A\&A 299, 277

Souchay J., Kinoshita, 1995, "Corrections and new contributions in rigid Earth Nutation Theory", A\&A (in press)

Wahr J.M., 1979, Ph.D. Thesis, University of Boulder, Colorado, U.S.A.

Walter H.G., Ma C., 1994, A\&A 284, 1000

Woolard E.W, 1953, Astron. Papers Amer. Eph. 15, p. 1

Zhu S.Y., Groten E., Reigber C., 1990, AJ 99, 1024 